\title{
Impact of Erythropoietin in the management of Hypoxic Ischaemic Encephalopathy in resource-constrained settings: protocol for a randomized control trial
}

Beatrice Ezenwa $a^{1,2^{*}}$ (D), Chinyere Ezeaka ${ }^{1,2}$, Iretiola Fajolu ${ }^{1,2}$, Anne Ogbenna $^{3}$, Omodele Olowoyeye ${ }^{4}$, Obiyo Nwaiwu ${ }^{5}$, Zainab Opoola ${ }^{2}$ and Gbenga Olorunfemi ${ }^{6}$

\begin{abstract}
Background: Perinatal asphyxia, more appropriately known as hypoxic-ischemic encephalopathy (HIE), is a condition characterized by clinical and laboratory evidence of acute or sub-acute brain injury resulting from systemic hypoxemia and/or reduced cerebral blood flow. HIE is a common and devastating clinical condition in resource-poor countries with poor treatment outcome. This paper describes the protocol for an ongoing study that aims to evaluate the neuroprotective effects of Erythropoietin (EPO) as compared to routine care in the management of moderate to severe HIE among term infants.

Methods: This study is a double-blind randomized controlled trial that will be conducted in the neonatal wards of the Lagos University Teaching Hospital (LUTH), Lagos, Nigeria, over a two-year period after ethical approvals and consents. One hundred and twenty-eight term newborns ( $\geq 37$ weeks gestation) diagnosed with moderate/ severe HIE at admission will be allocated by randomization to receive either EPO or normal saline. All the participants will be offered standard care according to the unit protocol for HIE. Baseline investigations and close monitoring of the babies are done until discharge. Participants are followed up for 2 years to monitor their outcome (death or neurological development) using standard instruments.

Discussion: Previous trials had shown that EPO confers neuroprotective benefits and improve neurological and behavioral outcome in infants with HIE both singly or as an adjuvant to therapeutic hypothermia. This study hypothesized that administering EPO to newborns with moderate /severe HIE can positively influence their clinical and neurological outcomes and will provide evidence to either support or disprove the usefulness of Erythropoietin as a sole agent in the treatment of $\mathrm{HIE}$, especially in resource-limited environment with the highest burden of the disease. (Continued on next page)
\end{abstract}

\footnotetext{
* Correspondence: beatriceezenwa@yahoo.com

'Neonatology unit, Department of Paediatrics, College of Medicine University of Lagos, Lagos, Nigeria

2Department of Paediatrics, Lagos University Teaching Hospital, Lagos,

Nigeria

Full list of author information is available at the end of the article
}

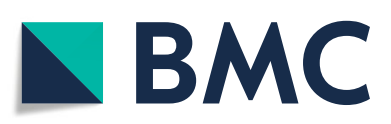

() The Author(s). 2020 Open Access This article is licensed under a Creative Commons Attribution 4.0 International License, which permits use, sharing, adaptation, distribution and reproduction in any medium or format, as long as you give appropriate credit to the original author(s) and the source, provide a link to the Creative Commons licence, and indicate if changes were made. The images or other third party material in this article are included in the article's Creative Commons licence, unless indicated otherwise in a credit line to the material. If material is not included in the article's Creative Commons licence and your intended use is not permitted by statutory regulation or exceeds the permitted use, you will need to obtain permission directly from the copyright holder. To view a copy of this licence, visit http://creativecommons.org/licenses/by/4.0/. The Creative Commons Public Domain Dedication waiver (http://creativecommons.org/publicdomain/zero/1.0/) applies to the data made available in this article, unless otherwise stated in a credit line to the data. 
(Continued from previous page)

Trial registration: The study has been registered with the Pan African Clinical trials registry on the 2nd of December 2018, with registration number PACTR201812814507775.

Keywords: Perinatal asphyxia, Hypoxic-ischemic encephalopathy, EPO and neurodevelopment

\section{Background}

Perinatal asphyxia (PA), more appropriately known as hypoxic-ischemic encephalopathy (HIE), is a condition characterized by clinical and laboratory evidence of acute or sub-acute brain injury resulting from systemic hypoxemia and/or reduced cerebral blood flow [1]. The insult to the brain can occur in-utero, intrapartum or postnatally. Hypoxic-Ischemic Encephalopathy is the commonest etiology for neonatal encephalopathies and accounts for $23 \%$ of all term newborn deaths worldwide [2]. Severe HIE occur in $0.1-0.3 \%$ of births in resource-rich countries [2, $3]$. However, the incidence of HIE is greater in low and middle-income countries (LMICs) [4] occurring in nearly $35 \%$ of neonatal admissions in India while different hospital-based studies in Nigeria documented between 2.6 and 30\% [5-8]. Furthermore, Ekure et al [9] reported that HIE accounted for nearly $39 \%$ of perinatal mortalities at a tertiary hospital in Lagos, South-Western Nigeria. HIE can be mild, moderate or severe. However, the majority (about 90\%) of cases of HIE that present to hospitals in Nigeria were moderate to severe [10]. The morbidity and mortality from HIE increases with increasing severity [10].

Survivors of moderate/ severe HIE have a high risk of developing severe cognitive and/or motor impairment, seizure disorders, deafness, and vision loss $[11,12]$ Neurologic abnormality at discharge is a strong predictor of long-term neurodevelopmental delay [13]. Many biomarkers of neurological damage resulting from asphyxia have been identified and investigated $[14,15]$. Biomarkers such as nucleated red blood cells (NRBC) has been demonstrated to be markedly elevated in asphyxiated newborns and can be useful in predicting adverse neurological outcomes [13-15]. Inflammatory cytokines such as Interleukin-6 (IL-6) have been shown to accumulate early in asphyxia [16, 17]. Chiesa et al. [18] reported that IL-6 concentrations were more than 300-folds in babies with HIE as compared to normal infants. Furthermore, Creatinine kinase BB (CK-BB) has been shown to predict HIE early as its rise occurs in the first hours after brain injury [19].

Therapeutic hypothermia (HT) has emerged as the gold standard for treating HIE [20] Thus if HT is commenced within 6 hours of injury, morbidity and mortality among infants with HIE can be significantly reduced [21-24]. HT is not readily available in most LMICs such as Nigeria. It is imperative that efforts should be geared towards early diagnosis and recognition of the sequelae of HIE, and improvement in the quality of life of survivors of HIE. In
Nigeria, the treatment of HIE is largely symptomatic and supportive despite the availability of beneficial treatment modalities elsewhere. Indeed, parents of babies with HIE may not be able to afford the high cost of the therapies.

Recently, some drugs such as Erythropoietin (EPO) have been found to possess positive neuroprotective, neuro-regenerative and anti-inflammatory effects in asphyxiated newborns [25-31]. EPO, hitherto widely used for Anemia of prematurity, achieves its neuroprotective effects through its anti-excitotoxic, antioxidant and antiapoptotic effects on neurons and oligodendrocytes [25$30,32]$. It also has anti-inflammatory effects on astrocytes and microglial cells [25-28, 31]. EPO prevents NO-induced cell death, protects neurons from glutamate toxicity, [33] and has demonstrable effects on neurogenesis, differentiation and repair after injury [29, 30, 34, 35]. Several studies on human and animal models demonstrated improvement in both short and long-term neurodevelopmental outcomes among asphyxiated babies that were exposed to EPO [33, 36, 37]. Even when EPO was commenced as late as 1-week post asphyxial insult in rodents, there was still beneficial effects in behavioral outcome, neuronal protection and regeneration [38]. The systematic review by Garg et al. [39] indicated that EPO confers long-term neurodevelopmental protection on neonates with moderate/severe HIE. None of the trials conducted on EPO among newborns, have shown any significant side effect despite the high doses employed for asphyxia [33, 40, 41].

Though EPO can be used synergistically with HT, [41] studies have shown good and beneficial effects when used as a single agent in the treatment of HIE [33, 42]. This is especially important in settings where HT is non-existent or when intervention is delayed due to late presentation. Despite the poor outcome of HIE in Nigeria, there is no local evidence supporting the introduction of EPO as a routine drug for the prevention of early and late neurological complications of perinatal asphyxia in the country. This study aims to evaluate the neuroprotective effects of EPO in comparison to routine care in the management of HIE in term infants.

\section{Null hypothesis}

Parenterally administered high dose EPO in newborns with HIE does not influence immediate or long-term outcome. 


\section{Specific objectives}

1. To describe the spectrum of asphyxia morbidities at the Lagos University Teaching Hospital

2. To compare the neurological outcomes of babies with moderate/severe HIE that had adjunctive treatment with EPO as compared to routine care in the immediate neonatal period and at $6,12,18$ and 24 months of age

3. To document common complications and adverse drug reactions in the treated infants

\section{Methods/ design \\ Study design}

This study is a double-blind randomized controlled parallel-group trial with one to one allocation ratio. The study is prospectively registered with the PACTR.

\section{Study setting}

This study is being conducted in the neonatal wards and clinics of the Lagos University Teaching Hospital (LUTH), Lagos, Nigeria and is ongoing as at the time of this submission. LUTH is a tertiary care hospital with facilities for neonatal care. The LUTH neonatal ward is the largest in the country with a capacity to admit more than 80 babies at a time. It has inborn and out-born sections with equal capacity for admissions.

\section{Population and sample size}

Table 1 shows the inclusion and exclusion criteria. All consecutively admitted term neonates with a diagnosis of severe perinatal asphyxia and presenting within $24 \mathrm{~h}$ of life in LUTH will be recruited for the study if they meet inclusion criteria.

\section{Sample size and power calculation}

There was no previous study in our environment describing the efficacy of EPO administration on the outcome of HIE. Furthermore, there is a paucity of recent published data on mortality and neurodevelopmental impairment from perinatal asphyxia in our environment. Mortality rate from asphyxia was reported to be between 31.1 and $62.8 \%$ in some hospitals in Nigeria $[5,9,10$, 44]. Since no study reported the prevalence of neurodevelopmental impairment of asphyxiated babies at 2 years of life, we expected that the prevalence of a combination of the outcome of "death and neurodevelopmental impairment" at 2 years of life among moderate/ severe HIE in a resource-poor environment such as Nigeria should be higher than the prevalence of death only (31.1$62.8 \%$ ). Thus, we assumed that the prevalence of "death and neurodevelopmental impairment at 2 years of life" among moderate/ severe HIE without EPO treatment in Nigeria will be about $65 \%$. Additionally, Zhu et al. [40]
Table 1 Participants' Inclusion and exclusion criteria for treatment

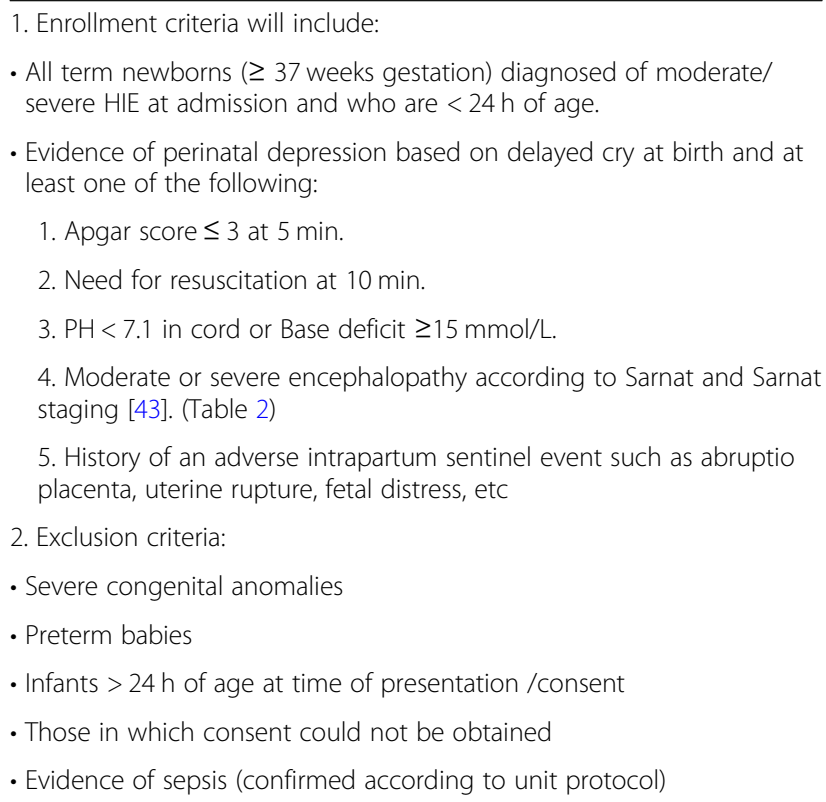

in Zhengzhou, China found that 24.6\% ( $n=18 / 73)$ of babies who had EPO either died or had neurodevelopmental impairment while $43.8 \%$ who had placebo died or had neurodevelopmental impairment, giving a relative risk of 0.62 (95\% CI: 0.41-0.94). Similarly, the range of protective relative risk that was reported or assumed by previous studies was between 0.65 to $0.71[41,45]$. Hence, we utilized the power calculator in Stata version 16 statistical software (Stata Corp, USA) to calculate the minimum sample size to be 128 babies based on the assumption that $65 \%$ of infants with moderate/ severe HIE may likely die or develop neurodevelopmental impairment without treatment; assuming a protective relative risk of $0.6,80 \%$ power and $10 \%$ loss to follow -up.

We utilized the Sarnat and Sarnat staging [43] of moderate or severe HIE for the recruitment of eligible participants (Table 2).

\section{Risk of bias}

This is a double-blind randomized control trial. Each participant is allocated into the intervention or control group by simple randomization using randomly generated number cards in sequentially numbered sealed opaque envelopes. The randomization list was created and generated online for the study by the Biostatistician based in South Africa. The outcome assessors (Paediatric Neurologist, Radiologist and the Biostatistician) are blinded to the group allocation during the study period. The managing physicians, however, are not blinded to the intervention drugs. 


\section{Intervention and procedure}

The approach to the management of HIE in our center is supportive care. Therapeutic hypothermia is not available. Supportive care includes maintaining normothermia, fluid, electrolyte and glucose balance, respiratory support with continuous positive airway pressure (CPAP) and oxygen, control of seizures and management of other complications as they arise [46]. During this study, participants randomized into EPO group, receives $1000 \mathrm{IU} / \mathrm{kg}$ of Erythropoietin intravenously statim on admission then daily for 5 days. This dose regimen was modified from the pharmacokinetic study by Wu et al. [37] Placebo/ control group receives 2 $\mathrm{ml}$ of $0.9 \%$ Saline statim on admission then daily for 5 days.

\section{Clinical monitoring}

All the participants are offered standard care according to the unit protocol for HIE. Fluid and electrolyte balance are maintained, oxygen therapy and other respiratory support modes are provided as necessary. Blood pressure is monitored during drug administrations and subsequently through a non-invasive blood pressure monitoring system. Daily monitoring and assessments are conducted until the 8th day of life using the Thompson's score [47]. A peak score above 15 predicts a bad outcome, whereas maintaining a score below 10 which becomes 0 at 1 week of age suggests a good prognosis. The following clinical course and baseline characteristics are recorded on a predesigned proforma: the grade of HIE (moderate or severe), the type of respiratory support needed, the presence of seizures, the time to establishment of full oral feedings through sucking and neurologic examination at discharge; the age at commencement of intervention, place of delivery, sex, gestational age at delivery, birth weight, head circumference, mother's age, parity and intrapartum events are all recorded.

\section{Laboratory markers}

Laboratory assessments for $\mathrm{E} / \mathrm{U} / \mathrm{Cr}, \mathrm{Ca}^{2+}$ and $\mathrm{PO}_{4}{ }^{-}$, Complete Blood count with NRBC count and NRBC count per 100 white blood cells (WBC) are done at admission using a venous sample. The ratio of NRBC/ $100 \mathrm{WBC}$ is performed by a haematologist. The levels of NRBCs per 100 white blood cells (WBCs) correlates with acute as well as chronic asphyxia and can be used as a reliable marker of perinatal asphyxia and neurological outcome $[13,15]$.

\section{Cranial ultrasonography}

All participants undergo a cranial ultrasound within $72 \mathrm{~h}$ of life looking for structural anomalies and cerebral echo densities. The ventricles are evaluated for size and configurations, the brain parenchyma checked for echogenicity, and presence of cystic encephalomalacia. Any echogenicity within the brain parenchyma, enlargement of the ventricles or the presence of encephalomalacia are considered as abnormal. Cranial ultrasound was chosen for this study over other imaging modalities due to its point of care application, relative affordability and ready availability in our setting. It is more affordable than MRI and is non-ionizing, unlike CT scan. However, it is important to note that it may not be the best tool for assessing intracranial abnormalities in term infants, as the extra-axial structures may not be well appreciated [48]. The cranial ultrasound is repeated at discharge for all participants to enable comparison. The scans are performed by a dedicated sonologist who is blinded to the intervention groups.

\section{Outcome}

The outcome measures are assessed at different periods (Table 3). Full neurological examination is performed at

Table 2 Sarnat and Sarnat staging [43] of moderate or severe HIE

\begin{tabular}{lll}
\hline Category & Moderate HIE & Severe HIE \\
\hline $\begin{array}{ll}\text { 1. Level of consciousness } \\
\text { 2. Spontaneous activity }\end{array}$ & Lethargy or obtunded & Stupor or Coma \\
3. Tone & Decreased & Absent \\
4. Posture & Hypotonia & flaccidity \\
5. Primitive reflexes & Distal flexion & Decerebrate state \\
$\begin{array}{l}\text { a. Suck } \\
\text { b. Moro reflex }\end{array}$ & Absent \\
6. Autonomic nervous system & Weak or biting & Absent \\
a. Pupils & Incomplete & \\
b. Heart rate & & Deviated, dilated, or nonreactive to light \\
c. Respirations & Constricted & Variable heart rate \\
7. Seizures & Bradycardia & Apnoea \\
8. EEG activity & Periodic breathing & Absent or uncommon \\
\hline
\end{tabular}

Presence of $\geq 1$ of these signs in any 3 of the above 8 categories is required for diagnosis 
discharge and at specified intervals (6,12,18,24 months) until the age of 2 years to assess for neurodevelopmental impairments using the Malawi Developmental Assessment Tool (MDAT) which has been validated for African children [49]. Another assessment tool that has been validated for the neurological assessment of neonates is the Bayley Scales of Infant and Toddler Development 3rd Edition.

(Bayley III) assessment tool. However, MDAT tool was preferred for this study since it takes cognizance of the culturally relevant differences in the neurodevelopmental assessment of African children. The Paediatric neurologist that assesses the neurodevelopmental status of the children will be blinded to the treatment arms.

\section{Primary outcome measures}

- The primary outcome is a composite outcome of death or neurodevelopmental impairment at 18-24 months of life. Neurodevelopmental impairment (NDI) is defined as the presence of any one of the following: hypertonia or spasticity, epilepsy, delayed milestones, cerebral palsy, Gross Motor Function Classification System (GMFCS) $\geq 2$, MDAT Z-score for age $\leq 1.64$ or scores less than expected for age using the MDAT chart [49].

\section{Secondary outcome measures}

a) Survival at discharge and time to discharge. Those that survived to discharge is assessed as: neurologically normal (those who had normal tone and posture, were free from seizures, has established full feed by sucking and have normal neonatal reflexes - rooting, suck, grasp, tonic neck reflex, Moro and stepping reflexes) while neurologically abnormal are those with an abnormal tone and posture, poor suck or any abnormal neonatal reflexes at discharge)

b) Association between the levels of NRBC and $\mathrm{NRBC} / 100 \mathrm{WBC}$ with neonatal outcome

c) Cranial USS evidence of ventricular enlargement, parenchymal echogenicity or cystic encephalomalacia.

d) Safety of the medications based on the presence or absence of any adverse event such as:

- Hypertension: systolic blood pressure in a neonate which is above 95th percentile for age and sex on three separate occasions;

- Hypotension: a systolic blood pressure in a neonate which is below the 10th percentile for age and sex on three separate occasions

- Apnoiec attacks

- Thrombotic events;

- Polycythemia: venous hematocrit of greater than $65 \%$.

a) Any other adverse effect noted during the hospital stay or follow up.

b) Those with cerebral palsy are further categorized based on features present on standardized neurologic examination, and classified as mild, moderate, or severe, with hemiplegia or diplegia, using the Gross Motor Function Classification System (GMFCS) assessment system.

\section{Data and safety monitoring plan}

Study data are monitored by the Paediatric Pharmacologist and the Biostatistician who are not involved with the day to day management of the recruited patients. An interim analysis for neonatal outcome is scheduled after 6 months of commencement of study in the absence of documented serious adverse effects. A decision to terminate

Table 3 Outcome measures at different time periods

\begin{tabular}{|c|c|c|c|c|c|c|c|c|}
\hline Domain & Outcome measure & $\begin{array}{l}\text { Stage } \\
\text { of HIE }\end{array}$ & $\begin{array}{l}\mathrm{T}_{1} \\
\text { Discharge }\end{array}$ & $\begin{array}{l}\mathrm{T}_{2} 4 \\
\text { months }\end{array}$ & $\begin{array}{l}\mathrm{T}_{2} 6 \\
\text { months }\end{array}$ & $\begin{array}{l}\mathrm{T}_{\mathbf{3}} 12 \\
\text { months }\end{array}$ & $\begin{array}{l}\mathrm{T}_{4} 18 \\
\text { months }\end{array}$ & $\begin{array}{l}\mathrm{T}_{\mathbf{5}} 24 \\
\text { months }\end{array}$ \\
\hline Survival & Survival or death & $x$ & $x$ & $x$ & $x$ & $x$ & $x$ & $X$ \\
\hline $\begin{array}{l}\text { Neurologic exam at } \\
\text { discharge }\end{array}$ & Neurologically normal or abnormal & $x$ & $x$ & & & & & \\
\hline Cranial Ultrasonography & Cranial USS abnormality & $x$ & $x$ & & & & & \\
\hline $\begin{array}{l}\text { Neurologic examination at } \\
\text { clinic visits }\end{array}$ & $\begin{array}{l}\text { Malawi Developmental Assessment Tool (MDAT) } \\
\text { scores }\end{array}$ & & & $x$ & $x$ & $x$ & $x$ & $x$ \\
\hline $\begin{array}{l}\text { Laboratory levels of EPO, } \\
\text { NRBC, and NRBC/100 WBC }\end{array}$ & $\begin{array}{l}\text { Levels of NRBC and NRBC/100WBC in relation to } \\
\text { outcome }\end{array}$ & $x$ & $x$ & & & & & \\
\hline Adverse reactions to EPO & $\begin{array}{l}\text { Safety of the medications based on the presence or } \\
\text { absence of any adverse event }\end{array}$ & & $X$ & $x$ & $x$ & $x$ & $x$ & $X$ \\
\hline $\begin{array}{l}\text { Gross Motor Function } \\
\text { Classification System } \\
\text { (GMFCS) assessment system }\end{array}$ & $\begin{array}{l}\text { Those with cerebral palsy are further categorized } \\
\text { based on features present on standardized } \\
\text { neurologic examination using GMFCS }\end{array}$ & & & $x$ & $x$ & $x$ & $x$ & $x$ \\
\hline
\end{tabular}

$\mathrm{T}_{1-} \mathrm{T}_{5}$ - The five time periods for assessment; NRBC Nucleated red blood cells, GMFCS Gross motor function classification system. 
the trial will be taken by the Paediatric Pharmacologist and the principal investigator.

\section{Serious adverse events}

A serious adverse event for this study is defined as any life-threatening events such as thrombotic events, severe hypertension or hypotension leading to death experienced by the infant following drug administrations or any other adverse event as previously described by other researchers [45]. All adverse events, both serious and non-serious, expected or unexpected, are recorded during the clinical trial and will be transmitted by the investigators to the designated competent authorities following hospital guidelines.

\section{Statistical analysis}

Statistical analysis will be performed using Stata version 16.0 (Stata Corp, USA) statistical software after importing the data from the Excel spreadsheet. Descriptive statistics will be computed for socio-demographic characteristics and expressed as frequency tables and charts. Continuous variables that are normally distributed will be expressed as mean \pm standard deviation (SD) while non-normally distributed continuous variables will be expressed as median and interquartile range (IQR). Association between categories of HIE and NRBC/ 100WBC will be tested using Students t-test. Also, the association between the grades of HIE and the degree of neurodevelopmental impairment will be conducted using the Pearson's Chi-square. Pearson's Chi-square will be used to compare the Gross motor function among the categories of HIE. Time to discharge, time to death and time to achieving major neurological milestones will be evaluated using the survival analysis techniques. Kaplan Meir's plot and Cox proportional hazard regression modelling will be conducted with severity (moderate or severe) of HIE as a primary explanatory variable. At the end-point, after 2 years of follow-up, the association between intervention arm and the end point parameters will be assessed using univariable and multivariable logistic regression modelling. Two-tailed test of hypothesis will be assumed and a $P$-value $<0.05$ will be taken as statistically significant level.

\section{Discussions}

HIE is prevalent in resource-poor countries. The absence of facilities for therapeutic hypothermia reduces the chances for survival and increases the risk of morbidity. The use of EPO has been shown by several trials conducted in newborn infants with HIE to be beneficial in reducing morbidity and improve neurodevelopmental outcome even in infants that did not receive therapeutic hypothermia [40]. The previous studies did not document significant adverse reactions with the use of the drug. The systematic review by Garg et al [39] concluded that EPO improves neurodevelopmental outcome and is quite safe in neonates with hypoxic-ischaemic encephalopathy. More evidence to strengthen these findings will enhance its continued use. This study is expected to provide further evidence to either support or disprove the usefulness of Erythropoietin as a sole agent in the treatment of HIE. Either way, it will aid decision making and counselling of parents by newborn care providers treating infants with HIE, especially in resource-limited environment. Moreover, evidence-based, cost-effective measures that will not only curtail mortality but will also enhance the quality of life of survivors of HIE should be encouraged.

\section{Abbreviations \\ PA: Perinatal asphyxia; HIE: Hypoxic ischaemic encephalopathy; EPO: Erythropoietin; LUTH: Lagos University Teaching Hospital; LMIC: Low and middle-income countries; NRBC: Nucleated red blood cells; CK-BB: Brain Creatinine kinase; IL: Interleukin; HT: Therapeutic Hypothermia; CPAP: Continuous positive airway pressure; WBC: White blood cell; MDAT: Malawi Developmental Assessment Tool; USS: Ultrasound; GMFCS: Gross Motor Function Classification System; WHO: World Health Organization; GCP: Good Clinical Practice; IQR: Interquartile range; HREC: Health research and ethics committee}

\section{Acknowledgements}

Not applicable.

\section{Authors' contributions}

EB contributed to the study development including concept and design, participated in the acquisition of data, drafted the manuscript and approved the final version to be published; EC contributed to the development of the study concept and design, revised the manuscript for intellectual content and approved the final version to be published; FI contributed to the study concept and design, revised the manuscript for intellectual content and approved the final version to be published; OO contributed to the study design and acquisition of data, revised the manuscript for intellectual contents and approved the final version to be published; OA contributed to the development of the concept and data acquisition, revised the manuscript for intellectual contents and approved the final version to be published; NO contributed to the study design, revised the manuscript and approved the final version to be published. ZO contributed to the study concept, revised the manuscript and approved the final version to be published. OG contributed to the study development, revised the manuscript for intellectual contents and approved the final version to be published.

\section{Funding}

This work was supported by the University of Lagos Central Research Committee (CRC) grant number 2019/05. The funding body played no role in the design, sample collection, analysis, and interpretation of data and the writing of the manuscript.

Availability of data and materials

Data sharing does not apply to this article as no datasets were generated or analysed during the current study.

Ethics approval and consent to participate

Approval for the study was obtained from the Human Research and Ethics Committee of Lagos University Teaching Hospital, Lagos, Nigeria (ethics number ADM/DCST/HREC/APP/2064). Written as well as verbal informed consent are obtained from the parents or caregivers before recruiting any baby into the study.

Consent for publication

Not applicable. 


\section{Competing interests}

The authors declared no competing interest for this work.

\section{Author details}

${ }^{1}$ Neonatology unit, Department of Paediatrics, College of Medicine University of Lagos, Lagos, Nigeria. ${ }^{2}$ Department of Paediatrics, Lagos University Teaching Hospital, Lagos, Nigeria. ${ }^{3}$ Department of Haematology \& Blood transfusion, College of Medicine University of Lagos, Lagos, Nigeria. ${ }^{4}$ Department of Radiodiagnosis, College of Medicine University of Lagos, Lagos, Nigeria. ${ }^{5}$ Department of Pharmacology, Therapeutics \&Toxicology, College of Medicine University of Lagos, Lagos, Nigeria. ${ }^{6}$ Division of Epidemiology and Biostatistics, School of Public Health, University of Witwatersrand, Johannesburg, South Africa.

\section{Received: 26 February 2020 Accepted: 27 April 2020 Published online: 04 May 2020}

\section{References}

1. Executive summary. Neonatal encephalopathy and neurologic outcome, second edition. Report of the American College of Obstetricians and Gynecologists' Task Force on Neonatal Encephalopathy. Obstet Gynecol. 2014;133(5):e1482-8.

2. Lee AC, Kozuki N, Blencowe $H$, et al. Intra-partum related neonatal encephalopathy incidence and impairment at regional and global levels for 2010 with trends from 1990. Pediatr Res. 2013;74(1):5072

3. Lawn J, Shibuya K, Stein C. No cry at birth: global estimates of intrapartum stillbirths and intrapartum related neonatal deaths. Bull WHO. 2005;83: 409 e17.

4. Paul VK. Neonatal morbidity: report of the National Neonatal and perinatal database. Indian Pediatr. 1999;36(2):167-9.

5. Mcgil-Ugwu Gl, Abedi HO, Ugwu EN. Incidence of birth asphyxia as seen in central hospital and GN Children's clinic both in Warri Niger Delta of Nigeria: an eight year retrospective review. Global J Health Sci. 2012;4(5): 140-6.

6. Onyearugha CN, Ugboma HAA. Severe birth asphyxia: risk factors as seen in a tertiary institution in the Niger Delta area of Nigeria. Continental. J Trop Med. 2010:4:11-9.

7. West BA, Opara PI. Perinatal asphyxia in a specialist hospital in Port Harcourt, Nigeria. Niger J Paed. 2013;40(3):206-10.

8. Emechebe GO, Ezeogu J, Odinaka KK. Birth asphyxia in Nigeria; a review. Trop J Med Health Sci Res. 2016;5(1):1-22.

9. Ekure EN, Iroha EO, Egri-Okwaji MTC, Ogedengbe OK. Perinatal mortality at the close of the 20th century in Lagos University teaching hospital. Niger J Paed. 2004;31(1):14-8.

10. Uleanya ND, Aniwada EC, Ekwochi U, ND U. Short term outcome and predictors of survival among birth asphyxiated babies at a tertiary academic hospital in Enugu, SouthEast, Nigeria. Afr Health Sci. 2019;19(1):1554-62. https://doi.org/10.4314/ahs.v19i1.29.

11. Rennie JM, Hagmann CF, Robertson NJ. Outcome after intrapartum hypoxic ischaemia at term. Semin Fetal Neonatal Med. 2007;12(5):398-407.

12. Dixon G, Badawi N, Kurinczuk JJ, et al. Early developmental outcomes after newborn encephalopathy. Pediatrics. 2002;109(1):26-33.

13. Volpe JJ. Neurology of the newborn. Philadelphia: Saunders; 2001. p. 33182

14. Rai R, Tripathi G, Singh DK. Nucleated RBC count as predictor of neurological outcome in perinatal asphyxia. Indian Pediatr. 2014;51:231-2.

15. Boskabadi H, Zakerihamidi M, Sadeghian MH, Avan A, Ghayour-Mobarhan M, Ferns GA. Nucleated red blood cells count as a prognostic biomarker in predicting the complications of asphyxia in neonates. J Matern Fetal Neonatal Med. 2017;30(21):2551-6.

16. Gorio A, Gokmen N, Erbayraktar S, et al. Recombinant human erythropoietin counteracts secondary injury and markedly enhances neurological recovery from experimental spinal cord trauma. Proc Natl Acad Sci U S A. 2002;99: 9450-5

17. Sola A, Wen T, Hamrick S, Ferriero D. Potential for protection and repair following injury to the developing brain: a role for erythropoietin? Pediatr Res. 2005;57:110R-7R.

18. Chiesa C, Pellegrini G, Panero A, De Luca T, Assumma M, Signore F, Pacifico L. Umbilical cord interleukin-6 levels are elevated in term neonates with perinatal asphyxia. Eur J Clin Investig. 2003;33:352-8.
19. Nagdyman N, Kömen W, Ko H, Müller C, Obladen M. Early biochemical indicators of hypoxic-ischemic encephalopathy after birth asphyxia. Pediatr Res. 2001;49:502-6.

20. American Academy of Pediatrics. Hypothermia and Neonatal Encephalopathy. Pediatrics. 2014;133:1146-50.

21. Thoresen M, HellströmWestas L, Liu X, de Vries LS. Effect of hypothermia on electroencephalogram in infants with asphyxia. Pediatrics. 2010;126(1):e1319.

22. Gluckman PD, Wyatt JS, Azzopardi D, et al. Selective head cooling with mild systemic hypothermia after neonatal encephalopathy: multicentre randomised trial. Lancet. 2005;365(9460):663-70.

23. Azzopardi DV, Strohm B, Edwards AD, et al. TOBY Study Group. Moderate hypothermia to treat perinatal asphyxial encephalopathy. N Engl J Med. 2009:361(14):1349-58.

24. Shankaran S, Laptook AR, Ehrenkranz RA, et al. National Institute of Child Health and Human Development Neonatal Research Network. Whole body hypothermia for neonates with hypoxicischemic encephalopathy. N Engl J Med. 2005:353(15):1574-84.

25. Nagai A, Nakagawa $E$, Choi $H B$, et al. Erythropoietin and erythropoietin receptors in human CNS neurons, astrocytes, microglia, and oligodendrocytes grown in culture. J Neuropathol Exp Neurol. 2001;60(4): 386-92.

26. Siren AL, Fratelli M, Brines M, et al. Erythropoietin prevents neuronal apoptosis after cerebral ischemia and metabolic stress. Proc Natl Acad Sci U S A. 2001;98(7):4044-9.

27. Sun Y, Calvert JW, Zhang JH. Neonatal hypoxia/ischemia is associated with decreased inflammatory mediators after erythropoietin administration. Stroke. 2005;36(8):1672-8.

28. Yis $U$, Kurul SH, Kumral A, et al. Effect of erythropoietin on oxygen-induced brain injury in the newborn rat. Neurosci Lett. 2008;448(3):245-9.

29. Shingo T, Sorokan ST, Shimazaki T, Weiss S. Erythropoietin regulates the in vitro and in vivo production of neuronal progenitors by mammalian forebrain neural stem cells. J Neurosci. 2001;21(24):9733-43.

30. Wang L, Zhang Z, Wang Y, Zhang R, Chopp M. Treatment of stroke with erythropoietin enhances neurogenesis and angiogenesis and improves neurological function in rats. Stroke. 2004;35(7):1732-7.

31. Ferriero DM. Neonatal brain injury. N Engl J Med. 2004:351(19):1985-95.

32. Maiese K, Li F, Chong ZZ. New avenues of exploration for erythropoietin. JAMA. 2005:293(1):90-5.

33. Elmahdy H, El-Mashad AR, El-Bahrawy H, El-Gohary T, El Barbary A, Aly H. Human recombinant erythropoietin in asphyxia neonatorum: pilot trial. Pediatrics. 2010;125(5):e1135-42.

34. Maier RF, Obladen M, Scigalla P, et al. for the European Multicenter Erythropoietin Study Group. The Effect of Epoetin Beta (Recombinant Human Erythropoietin) on the Need for Transfusion in Very Low Birth Weight Infants. N Engl J Med. 1994;330:1173-8.

35. Ohls RK, Ehrenkranz RA, Das A, et al. National Institute of Child Health and Human Development Neonatal Research Network. Neurodevelopmental Outcome and Growth at 18 to 22 Months' Corrected Age in Extremely Low Birth Weight Infants Treated With Early Erythropoietin and Iron. Pediatrics. 2004;144:1287-91

36. Kellert BA, McPherson RJ, Juul SE. A comparison of high-dose recombinant erythropoietin treatment regimens in brain-injured neonatal rats. Pediatr Res. 2007:61:451-5.

37. Wu YW, Mathur AM, Chang T, RC MK, Mulkey SB, Mayock DE, et al. Highdose erythropoietin and hypothermia for hypoxic-ischemic encephalopathy: a phase II trial. Pediatrics. 2016;137:e20160191.

38. Larpthaveesarp A, Georgevits M, Ferriero DM, Gonzalez FF. Delayed erythropoietin therapy improves histological and behavioral outcomes after transient neonatal stroke. Neuroiol Dis. 2016;93:57-63.

39. Garg B, Deepak Sharma D, Bansal A. Systematic review seeking erythropoietin role for neuroprotection in neonates with hypoxic ischemic encephalopathy: presently where do we stand. J Matern Fetal Neonatal Med. 2018;31(23):3214-24. https://doi.org/10.1080/14767058.2017.1366982.

40. Zhu C, Kang W, Xu F, et al. Erythropoietin improved neurologic outcomes in newborns with hypoxic-ischemic encephalopathy. Pediatrics. 2009;124(2): e218-26.

41. Wu YW, Bauer LA, Ballard RA, Ferriero DM, et al. Erythropoietin for Neuroprotection in neonatal encephalopathy: safety and pharmacokinetics. Pediatrics. 2012;130:683-91

42. Hobson A, Baines J, Weiss MD. Beyond hypothermia: alternative therapies for hypoxic ischemic encephalopathy. Open Pharmacol J. 2013;7:26. 
43. Sarnat HB, Sarnat MS. Neonatal encephalopathy following fetal distress. A clinical and electroencephalographic study. Arch Neurol. 1976;33(10):696705.

44. Egharevba IO, Kayode-Adedeji BO, Alikah SO. Perinatal asphyxia in a rural Nigerian hospital: incidence and determinants of early outcome. J NeonatalPerinatal Med. 2018;11(2):79-183.

45. Juul SE, Comstock BA, Heagerty PJ, Mayock DE, Goodman AM, Hauge S, Gonzalez F, Wu YW. High-Dose Erythropoietin for Asphyxia and Encephalopathy (HEAL): A Randomized Controlled Trial - Background, Aims, and Study Protocol. Neonatolology. 2018;113:331-8. https://doi.org/10.1159/ 000486820.

46. Agarwal R, Jain A, Deorari AK, et al. Post-resuscitation management of asphyxiated neonates. Indian J Pediatr. 2008;75:175-80. https://doi.org/10. 1007/s12098-008-0026-5.

47. Thompson CM, Puterman AS, Linley LL, Hann FM, van der Elst CW, Molteno $C D$, et al. The value of a scoring system for hypoxic ischaemic encephalopathy in predicting neurodevelopmental outcome. Acta Paediatr. 1997;86:757

48. Gupta P, Sodhi KS, Saxena AK, Khandelwal N, Singhi P. Neonatal cranial sonography: a concise review for clinicians. J Pediatr Neurosci. 2016;11(1):713. https://doi.org/10.4103/1817-1745.181261.

49. Gladstone M, Lancaster GA, Umar E, Nyirenda M, Kayira E, van den Broek NR, et al. The Malawi developmental assessment tool (MDAT): the creation, validation, and reliability of a tool to assess child development in rural African settings. PLoS Med. 2010;7(5):e1000273. https://doi.org/10.1371/ journal.pmed.1000273.

\section{Publisher's Note}

Springer Nature remains neutral with regard to jurisdictional claims in published maps and institutional affiliations.

Ready to submit your research? Choose BMC and benefit from:

- fast, convenient online submission

- thorough peer review by experienced researchers in your field

- rapid publication on acceptance

- support for research data, including large and complex data types

- gold Open Access which fosters wider collaboration and increased citations

- maximum visibility for your research: over $100 \mathrm{M}$ website views per year

At $\mathrm{BMC}$, research is always in progress.

Learn more biomedcentral.com/submissions 